\title{
Investigation of the Allelopathic Potential of Alhagi Maurorum on Pisum Sativum L. \\ R.Khalil ${ }^{1}$, M.Madany ${ }^{2}$, F.bassyoini ${ }^{1}$, A.Gamal ${ }^{1}$ \\ ${ }^{1}$ Botany Dept., Faculty of Science, Benha Univ, Benha, Egypt \\ ${ }^{2}$ Botany Dept., Faculty of Science, Cairo Univ, Giza, Egypt \\ E-mail: aminagamal39@yahoo.com
}

\begin{abstract}
The current study evaluate the effect of aqueous extract from the shoot of Alhagi maurorum at different rates $(0.01,0.05,0.10,0.15 \%, \mathrm{w} / \mathrm{v})$ on some physiological parameters of pea. The pot experiment revealed that Alhagi maurorum aqueous extract reduced all growth parameters of pea plant. Also, photosynthesis pigments, insoluble sugars, total carbohydrate, total protein and total phenolics were markedly reduced in response to treatment with aqueous Alhagi extract. On other hand, soluble sugars, soluble protein, proline and flavonoids increased upon treatment with Alhagi maurorum extract.
\end{abstract}

Keywords: Antioxidant enzymes, Flavonoid, Phenolic, Photosynthetic pigments, Pisum sativum, Proline.

\section{Introduction}

Plants create massive array of secondary metabolites that escape to the environment and affect the growth and development of neighboring plants and other organisms, a phenomenon known as "allelopathy" [1-2].

Plants can interact chemically together by releasing secondary metabolites (allelochemicals) into the growth environment [3-4]. These chemicals are products of the secondary metabolism and are non-nutritional primary metabolites [5-6] which are not necessary for development and reproduction of the allelopathic organism. The impact of allelochemicals compounds on germination, growth and development of plants is regulated by their complexity, interaction and concentration [7-8].

Allelochemicals are existing in all types of plants and tissues which most of them are totally or partially water-soluble which makes them easier to remove without additional surfactants [9-10], with small molecular weight, existing in different organs of some botanical species [11-12]. Which released in to environment from plant parts by a diversity of mechanisms, including root exudation, leaf leachates and volatilization, or through decomposition of plant remains [11]. Many studies have been generated to determine the inhibitory potential of different allelopathic crops and trees for weed management [13-16], so simply to synthetics herbicides without any remaining or toxic effects [17].

allelochemicals, germination, growth and development may be affected by disruption of numerous physiological processes including photosynthesis, respiration and altered in water status, enzymes activity and hormonal balance. Allelochemicals action on plants many biochemical reactions changed and finally affected on growth of target (receptor) plants [27-28]. In which rate of inhibition of allelochemicals on different plant species dependent on concentration of used plant aqueous extract [29].
[30] showed that by increasing concentrations of aqueous leaf extracts of Andrographis paniculate inhibited the seed germination, shoot length, root length and dry weight of wheat seedlings. At higher concentrations of Calotropis procera leaf extracts, a significant reduction in the growth of the test plants were recorded[31].

[32] reported that suppress of chlorophylls may decrease the photosynthesis process and substantially decrease all the metabolites such as, total sugars, soluble amino acids and proteins. Allelopathic stress of Mentha piperita L residual reduced the amount of chlorophylls and carotenoids in the rice seedlings [33].

Sugar contents formed by the plant during photosynthesis, are an essential component of plant nutrition. [34] observed that the pea seedlings treated with Hyptissuaveolens L. leachate led to decrease in the sugar contents when compared with the control plants. Allelopathic treatments led to a significantly decrease in the sugar content of the rice seedlings under highest concentration of Mentha piperita L. residual, with maximum 67.97 $\%$ in decrease as compared with control [33].

Amino acids are very important compounds in plant which considered as building blocks of proteins, and a variety of other functional compounds, also increase plant defend against pests, diseases and resist stresses [35], proline is one of the metabolic products that frequently accumulate in response to all variety of environmental stresses. [36] for both wheat and pea seedlings, found that different concentrations of Euphorbia helioscopia extract significantly increased the accumulation of amino acids. Protien compounds are a macro-molecule that participates in every aspect of plant growth and development. Proteins are involved in processes such as catalyzing chemical reactions (enzymes), facilitating membrane transport, intracellular 
structure and energy generating reactions involving electron transport.

[33] reported that, a significant reduction in protein content was recorded in rice seedlings under allelopathic stress caused by Mentha residue. The proteins content of Abelmoschus esculentus L. was inhibited in all treatments of Azadirachta indica L. when compared to control plants[37].

This inhibitory characteristic is intervening with important physiological and metabolic process of plant conducive to shut off. On the other, allelochemicals activation growth and investigation resistance against several abiotic stresses [18] at low concentrations.

Field pea (Pisum sativum L.) is one of the oldest domesticated crops cultivated in the world for thousands of years before the tenth and ninth BC [19]. Pisum sativum includes both wild species $(P$. fulvum and $P$. eratius) and cultivated species $(P$. abyssinicum) native originally from the Mediterranean region, primarily in the Middle East [20]. Leguminous plants such as peas plants an economic crop, a major source of protein consumed by humans and animals, also necessary for agricultural systems because of their ability to fix nitrogen, thus provides a biological alternative to chemical fertilization [21]. Alhagi maurorum plant integratet of family leguminasae and native to north africa,the middle east and south easteurope [22]. Moreover, A. maurorum distributed and appeared to have wide ecological extent in Egypt, it noted from Nile region, oasis, Mediterranean region, Eastern and Western Desert, Red sea Coast and Sinai, also in Saudi Arabia deserts [23]. Alhagi species contains many active constituents such as flavonoids, fatty acids, coumarins, sterols, vitamins, and alkaloids [24]. Phytochemical studies on $A$. maurorum show carbohydrates, tannins, unsaturated sterols, triterpenes, flavonoids, and flavanone glycosides [25]. [26] argued that the mixture of phenolic compounds was less inhibitory than individual phenolic compounds.

Phenolic compounds are considered as one of the biggest and widely dispersed groups of secondary metabolites in plants [38]. Biogenetically, phenolic compounds progress of two metabolic pathways: the shikimic acid pathway where, mainly, phenyl propanoids are formed and the acetic acid pathway, in which the main products are the simple phenol [39]. Most plants phenolic compounds are created through the phenyl propanoid pathway [40].The fusion of both pathways leads to the making of flavonoids, the most abundant group of phenolic compounds in nature [39].

Flavonoid compounds are low molecular weight secondary metabolites that are produced by plants, with over 10,000 structural variants now reported [41-42].their synthesis appears to be ubiquitous in plants and evolved early during land plant evolution, aiding in plant protection and signaling [43-44]. Due to their physical and biochemical properties, flavonoids also are able to interact with many diverse targets in subcellular locations to elicit various activities in microbes, plants and animals [45-46]. They also play important roles in modulating the levels of reactive oxygen species (ROS) in plant tissues [47], and provide coloring to various tissues including flowers [48].

There is convincing evidence that allelopathic interaction between plants play a crucial role in natural as well as in manipulated ecosystems [49]. Studies of these interactions, especially those in natural ecosystem, provided the basic data for the science of allelopathy [50]. These data were eventually applied to understand the problems of plant-plant interaction and to exploit these improving the production of ecosystem, plant- plant interactions will be considered two main factors are complicated in this interaction: donor plant, which creates and emission the allelochemicals, and the extradite plant that is somehow critical to it. The main purposes of research on allelopathy include the application of the observed allelopathic effects to agricultural production, reduction of the input of chemical pesticides and consequent environmental pollution, and provision of effective methods for the sustainable development of agricultural production and ecological systems [51].The technological advances made in allelopathy research in recent years have been created, analyzed, and developed by scientific establishments throughout the world, they present exciting and intellectually challenging problems which are solvable using modern techniques [52].

\section{Materials and methods}

The present work was conducted to evaluate the effect of Alhagi maurorum aqueous extract upon growth and some metabolic activities in pure strain of pea (Pisum sativum L.).

\subsection{Plant materials}

Pea seeds (Pisum sativum L.) was kindly obtained from the Agricultural Research center, Ministry of Agriculture, Giza, Egypt. Wild plants as Alhagi maurorum was collected from the field in EL Qalyubiyah, Egypt). Take only shoot system of A. maurorum plant in which oven dried at $50^{\circ} \mathrm{C}$ after 10 days for constant weight, the plant shoot grounded to very fine powder in mixer and stored in glass jars until use.

\subsection{Preparation of shoot extract}

The shoot extract from the collected shoot of Alhagi maurorum was prepared by using powder form which refluxed in $70 \%$ alcohol (methanol) for 24 hours at room temperature. After reflux, the solution was filtered through Whatman filter paper No. 1 and the collected solution evaporated to 
dryness at $50^{\circ} \mathrm{C}$ to recover dry powder, then completed to $100 \mathrm{ml}$ distilled water, which was stored at $4^{\circ} \mathrm{C}$ till further use.

\subsection{Greenhouse pot experiment}

The pot experiment was carried out under natural conditions, in greenhouse of Botany Department, Faculty of science, Benha University.

Plastic pots $(25 \mathrm{~cm}$ diameter X $30 \mathrm{~cm}$ depth) were field with $10 \mathrm{Kg}$ of a mixture of clay/sand $(1: 1, w / w)$. Calcium superphosphate $\left(15.5 \% \mathrm{P}_{2} \mathrm{O}_{5}\right)$ and potassium sulphate $\left(48 \% \mathrm{~K}_{2} \mathrm{O}\right)$ as a source of phosphorus and potassium fertilization were added before sowing at a rate of 6.0 and $3.0 \mathrm{~g} / \mathrm{pot}$ respectively. The pots were divided in to 5 group including the control and 4 concentrations of Alhagi maurorum (0.01, 0.05, 0.1, 0.15\%, w/v) .Each treatment has five replicates. Seeds of pea under investigation were surface sterilized with $1 \%$ of sodium hypo-chloride for $5 \mathrm{~min}$ and washed thoroughly with several changes of sterile distilled water. They were then soaked overnight (12 hours) in either (i) distilled water or (ii) crude extract of Alhagi maurorum $(0.01,0.05,0.1,0.15 \%, \mathrm{w} / \mathrm{v})$. Ten seeds of each treatment were sown in each pot at $3 \mathrm{~cm}$ depths. After emergence, the seedlings were thinned to five healthy seedlings per pot. Pots were maintained in a greenhouse under natural conditions. Plant irrigated with tap water as needed to maintain an optimal soil moisture regime throughout the experiment.

\subsection{Growth parameters}

Growth measurements were carried out after 45- day of sowing. This period considered half for the cultivation of peas. At the end of period, five pots of each group were harvested, and their roots were washed thoroughly with running water to remove adhering soil particles. The plants we cut into roots, stems, leaves. The lengths randomly roots, stems (cm/plant), as well as the number of leaves per plant and leaf area $\left(\mathrm{cm}^{2} /\right.$ plant) were measured. The fresh weight of root, stem and pods (g/plant) of pea were measured. After that, all samples were dried in an oven at $70^{\circ} \mathrm{C}$ to constant weight for dry weight ( $\mathrm{g} /$ plant) and water content of both root and stem were measured at this period the dry tissues of pea plant organs were grounded into fine powder and kept under dry conditions for biochemical analyses .

\subsection{Metabolic activities}

\subsubsection{Extraction and determination of photosynthetic pigments}

Total photosynthetic pigments were extracted and determination according to the method described by [53]. The absorbance measurements were carried out on Perkin- Elmer spectrophotometer (Model 200-20 Double Beam) at wavelength 440.5, 644 and $662 \mathrm{~nm}$.

The contents of chl a and chl b, as well as carotenoids respectively, were calculated using the following Equations for 100\% acetone the formula adapted by [54]:

Chlorophyll $\mathrm{a}=9.78 \times \mathrm{E}_{662^{-}} 0.99 \times \mathrm{E}_{644} \quad \mu \mathrm{g} / \mathrm{ml}$ Chlorophyll $\mathrm{b}=21.4 \times \mathrm{E}_{644}-4.65 \times \mathrm{E}_{662} \quad \mu \mathrm{g} / \mathrm{ml}$

Chlorophyll $(\mathrm{a}+\mathrm{b})=5.13 \times \mathrm{E}_{662}+20.41 \times \mathrm{E}_{644} \mu \mathrm{g}$ $/ \mathrm{ml}$

Carotenoids $=4.69 \times \mathrm{E}_{440.5}-0.268(\mathrm{chl} \mathrm{a}+\mathrm{chl} \mathrm{b})$ $\mu \mathrm{g} / \mathrm{ml}$

Where: $\mathrm{E}$ is the reading of the optical density at given wave length..

The concentrations of pigments were then expressed in $\mathrm{mg} / \mathrm{gm}$ fresh weight The results obtained from the above equations were expressed as $\mu \mathrm{g}$ pigment $\mathrm{ml}^{-1}$ extract, then calculated as $\mathrm{mg}$ pigment $\mathrm{g}^{-1}$ fresh weight.

\subsubsection{Extraction and estimation of carbohydrates}

Total water-soluble sugars were extracted by according to the method outlined by [55]. Reducing value of each sugar extract was determined according to the method adopted by [56]. The content of reducing sugar was determined from glucose standard curve and then calculated as $\mathrm{mg}$ sugar $\mathrm{g}^{-1}$ dry weight. The non-reducing sugars were determined according to the method obtained by [57]. One milliliter of each sugar extract was hydrolyzed by $1 \mathrm{ml}$ of $7 \mathrm{~N} \mathrm{HCl}$ and heated in a boiling water bath for $15 \mathrm{~min}$, cooled under running water. Neutralized by $1 \mathrm{ml}$ of $10 \mathrm{~N} \mathrm{NaOH}$ and finally completed up to known volume of distilled water, Whereas the insoluble carbohydrates in the remaining dry residue were hydrolyzed with $0.2 \mathrm{~N}$ $\mathrm{H}_{2} \mathrm{SO}_{4}$ in boiling water bath for one hour, cooled under running water and centrifuged at $5000 \mathrm{~g}$ for 15 min then the supernatant was completed up to known volume of distilled water [58]. The reducing values of the hydrolyzed samples were measured by Nelson's reaction.

\subsubsection{Extraction and determination of protein}

Extraction of water soluble and insoluble proteins was carried out according to the method described by [59]. Proteins determination was carried out according to the modified Folin-Lowry method adopted by [60]. The concentration of protein was determined using bovine serum albumin standard curve, then expressed as $\mathrm{mg} \mathrm{g}^{-}$ ${ }^{1}$ dry weight. 


\subsubsection{Extraction and determination of proline}

Free proline was determined according to[61]. The absorbance was recorded at $520 \mathrm{~nm}$ using toluene as a blank. The proline concentration was determined using a standard curve and calculated on a dry matter basis as mg proline $100 \mathrm{~g}^{-1}$ dry matter.

\subsubsection{Extraction and determination of phenolic compounds}

Phenolic compounds were extracted according to the method outlined by [62]. The FolinCiocalteu phenol method [63] was used for phenolic aglycone determination. One $\mathrm{ml}$ of phenolic extract was mixed with one $\mathrm{ml}$ of $10 \%$ Folin-Ciocalteu phenol reagent and one mlof $20 \%$ anhydrous sodium carbonate, and then completed up to a known volume with distilled water. The absorbance of blue colour was measured after 30 minutes at wavelength $650 \mathrm{~nm}$ against a water reagent blank. The phenolic content was obtained from the standard curve of catechol, and then calculated as $\mathrm{mg}$ phenolic $\mathrm{g}^{-1}$ dry weight. Subtraction of phenolic content after and before acid hydrolysis gave the content of phenolic glycosides.

\subsubsection{Extraction and determination of flavonoids}

Total flavonoid content was measured using aluminum chloride colorimetric assay [64]. The absorbance was measured immediately at $510 \mathrm{~nm}$ and the concentration of total flavonoids was calculated using standard curve of myricetin, then expressed as $\mathrm{mg} \mathrm{g}^{-1}$ dry weight.

On other hand, the treatments $0.01,0.05$ and $0.10 \%(\mathrm{w} / \mathrm{v})$ of the $A$. maurorum aqueous extract caused a significant decrease in root length estimated by $20.15 \%, 43.28 \%$ and $52.08 \%$ respectively to control pea plants.

On the other hand, fresh and dry weights of root of pea plants also showed a marked reduction at different concentration of Alhagi shoot extract. The maximum reduction in fresh and dry weights of root were shown in plant treated with 0.10 and 0.15 $\%(\mathrm{w} / \mathrm{v})$ Alhagi aqueous extract as their values were estimated by $61.66 \%$ and $65 \%$ in root dry weight and $56.94 \%$ and $70.83 \%$ in root fresh weight respectively as a compared to control plants.

Moreover, the results Data expressed in Fig (3) revealed that, treatment with different concentration of A. maurorum reduce number of leaves per plant, area of leaves per plant, fresh and dry weight of pods. The maximum reduction recorded at $0.15 \%$ (w/v) of Alhagi aqueous extract, whereas number of leaves and leaf area decreased about 14 and $86 \%$ respectively, as compared with untreated control plants. On the other hand, fresh and dry weight of pods decreased as compared with non-treated plant. The highest concentration of Alhagi aqueous extract $0.15 \%(\mathrm{w} / \mathrm{v})$ suppress all growth criteria in pisum plants as compared with the non-treated plant. Generally, the effect of phenolic compounds on germination and early seedling growth may be stimulatory or inhibitory depending on the compound utilized, concentration, and the test plant [65].

[31] showed that root and shoot lengths of the test species affected by allelopathic stress caused by Calotropis procera leaf extracts and at higher concentrations of leaf extracts, a significant reduction in the fresh and dry weight of the test species was recorded except a cucumber which exhibited non-significant increase in its fresh and dry weight. Reduction in most vegetative growth parameters could be due to the reduction in the cell size which might be attributed to changes in osmotic cell enlargement dependent on solute accumulation, i.e., due to drastic changes in ion relationship [66].

\subsection{Metabolic activities}

The biochemical changes in pea plants, in response to the different concentrations of Alhagi maurorum aqueous extract were analyzed at the 45 day-old pea plants.

\subsubsection{Photosynthetic pigment content}

Data represented in Fig (4) revealed that, chlorophyll a, chlorophyll $\mathrm{b}$, chlorophyll $\mathrm{a}+\mathrm{b}$, carotenoids and total pigment contents were significantly reduced by increasing the applied concentration of Alhagi maurorum aqueous extract level up to $0.15 \%(\mathrm{w} / \mathrm{v})$ as compared with untreated control plants.

\subsubsection{Statical analysis}

All experiments were conducted in a completely repeated and randomized design. The computer program SPSS (version 18) was used for statistical analyses of studied parameters. All the data are presented as mean $\pm \mathrm{SE}$ and subjected to analysis by one-way ANOVA followed by Duncan's multiple range test at $\mathrm{P}<0.05$. Where needed, data were transformed by $\log (\mathrm{x}+1)$ before statistical analysis.

\section{Results and discussion}

\subsection{Growth parameters}

The changes in Growth parameters of 45-dayold Pisum sativum plants in response to different concentrations of $A$. maurorum aqueous extract at the rates: $(0.01,0.05,0.10$ or $0.15 \% ; \mathrm{w} / \mathrm{v})$ are given in Fig (1). The obtained results show that the measured growth parameters; shoot length, fresh and dry weights significantly decreased by increasing $A$. maurorum aqueous extract level, the maximum reduction was observed in the plant subjected to $0.15 \%$ Alhagi concentration, as their values were estimated $57.21 \%$ in shoot length, 
$70.73 \%$ in fresh weight and $93.18 \%$ in dry weight as compared with the un treated control plants. Also, results shown in Fig (2) revealed that the root parameters; root length, fresh and dry weights of roots of treated pea plants subjected to various levels of $A$. maurorum aqueous extract were significantly reduced as compared with control plants. The highest inhibitory effect of $A$. maurorum aqueous extract was recorded in plant treated with $0.15 \%(\mathrm{w} / \mathrm{v})$ where the rate of decreased was 71.56 $\%$ in root length as a compared to untreated pea plants.

The highest inhibitory effect of Alhagi on all photosynthetic pigments chlorophyll a, chlorophyll $\mathrm{b}$, chlorophyll $\mathrm{a}+\mathrm{b}$ and carotenoids and hence total pigments were recorded in plant subjected to 0.15 $\%(\mathrm{w} / \mathrm{v})$ Alhagi aqueous extract and as estimated by $58 \%, 83.33 \%, 66.9 \%$ and $56.72 \%$ respectively, as compared with control plants. Our results showed that the decrease in chlorophyll $b$ was more pronounced in than chlorophyll a, that in turn affect the $\mathrm{Chl} \mathrm{a}+\mathrm{b}$ ratio. Similarly, the carotenoids content was negatively affected as both $\mathrm{Chl}$ a and $\mathrm{Chl} \mathrm{b}$. In the present work, the reduction in total photosynthetic pigments in the pea leaf relative to control plant may be due to the accumulation of phenolic aglycone fraction that could interfere with the chlorophylls and carotenoids biosynthesis or their degradation [67]. On other hand, reduction of these pigments because of increasing in the leaf resistances to $\mathrm{CO}_{2}$ transport when the plant put under biotic or abiotic stresses [68].

\subsubsection{Carbohydrate content}

The pattern of changes in the amount of various carbohydrate fractions in the shoots of 45-day-old pea plant treated with different concentrations of Alhagi maurorum aqueous extract were shown in The d Data clearly in Fig (5) show that by increasing the concentration of Alhagi up to $0.15 \%$ $(\mathrm{w} / \mathrm{v})$ lead to very little drop rate is almost negligible in total carbohydrates content to about $4.53 \%$, relative to the non- treated plant. This response was mainly due to a significant increase in soluble sugars contents over the control plants. In which amount of increasing in soluble sugars in treated pea plant under different concentrations of Alhagi maurorum aqueous extract $0.01,0.05,0.10$ and $0.15 \%(\mathrm{w} / \mathrm{v})$ were $10.30,15.88,22.47$ and $30.93 \%$ respectively, as compared with control plants. On the other hand, the insoluble sugar contents markedly decreased by raising Alhagi aqueous extract concentrations. The maximum inhibition in insoluble sugar was 37.71 and $45.58 \%$ at both 0.10 and $0.15 \%(\mathrm{w} / \mathrm{v})$ from Alhagi aqueous extract as compared with untreated plants. Decreasing in total carbohydrates reflect another reason for inhibition photosynthesis pigment in pea plants. [69-70] supported our result who reported that, reduction in sugar content under osmotic stress may be lead to decrease of photosynthesis and photo assimilates in the aerial parts.

\subsubsection{Protein and proline contents}

Data represented in Fig (6) clearly demonstrated that $A$. maurorum aqueous extract influences the protein content of Pisum sativum shoots. T the amount of total protein significantly decreased by raising Alhagi maurorum aqueous extract up to $0.15 \%(\mathrm{w} / \mathrm{v})$ that reached to $8.95 \%$ as compared to their respective control. In which 0.01 $\%$ (w/v) from Alhagi aqueous extract has a slight undetectable decrease on pea plants the amount of decreasing was $2.19 \%$ relative to those of the control plant. This response mainly due to a significant increase in the soluble protein contents over the control pea plants.

The amount of increasing in the soluble protein of pea plants treated with different concentrations of Alhagi maurorum extract 0.01, 0.05, 0.10, 0.15 $\%(w / v)$ calculated by $17.5,18.47,28.34$ and 33.44 $\%$ respectively to control pea plant. On the other hand, Insoluble protien in treated plant decreases by increasing Alhagi maurorum aqueous extract up to $0.15 \%(\mathrm{w} / \mathrm{v})$ that reached to $38.29 \%$ as compared to their respective non-treated pea plant.

The change in proline content of pea plant in response to treatment with different concentrations of $A$. maurorum aqueous extract is represented The data clearly in Fig (7). showed that a highly significant accumulation of proline under different concentrations of $A$. maurorum aqueous extract as compared to control plants. The maximum value was detected in plants treated with $0.15 \%(\mathrm{w} / \mathrm{v}) A$. maurorum aqueous extract which was calculated by $137 \%$ as compared with the control plants. These results are in agreement with those obtained by [71] have reported that the leaf litter leachate of Eucalyptus globulus decreased the protein content in both root and shoot of finger millet. In addition, [72] demonstrated that free amino acid contents raising during germination because of combined activities of hydrolytic enzymes.

\subsubsection{Phenolic content}

The data presented in Fig (8) showed that a highly significant increase in the phenolic aglycone content in pea shoots by increasing the Alhagi concentrations up to $0.15 \%(\mathrm{w} / \mathrm{v})$ that reached $82.97 \%$. In addition, the phenolic glycoside content was progressively decreased by raising the Alhagi concentrations up to $0.15 \%(\mathrm{w} / \mathrm{v})$, in which reduced by about $93.29 \%$ as compared to their respective control plant. This response reflected a lower significant depression of total phenolic content in pea shoots as compared with control plants, the amount of decreasing in total phenolics due to treatment with Alhagi maurorum concentrations 
$0.01,0.05,0.10,0.15 \%(\mathrm{w} / \mathrm{v})$ are $8.1,15.15,27.47$ and $28.48 \%$ respectively, as compared with control plants. Similar results were also obtained in our earlier research on osmotic stress inhibits the total synthesis of phenolic compounds, it was shown previously in extracts from germinating seeds of Vitis amurensis[73].

\subsubsection{Flavonoids contents}

Total flavonoids showed a marked accumulation in treated pea shoots under response to treatment with Alhagi aqueous extract Our data Fig (9) showed that different concentrations of Alhagi maurorum aqueous extract caused a significant increase by about 50,162, 281 and $337 \%$ for the concentrations $0.01,0.05,0.10$ and $0.15 \%(\mathrm{w} / \mathrm{v})$ respectively, as compared with their untreated pea plants. This results in agreement with the results obtained by [36] who reported that, total flavonoids showed a marked accumulation in response to treatment with Euphorbia helioscopia L. water extract. [74] have reported an up regulation of the flavonoid biosynthetic genes, because of $\mathrm{NaCl}$ stress. Moreover, [75] in Ligustrum vulgare leaves, as both water stress and sunlight irradiance led to a steep enhancement in the biosynthesis of flavonoids with an orthodihydroxy B-ring substitution. Recently, the enhancement in flavonoid biosynthesis was paralleled with the increase in glutathione-S-transferase, which is involved in the transport of flavonoids to the vacuole [76].

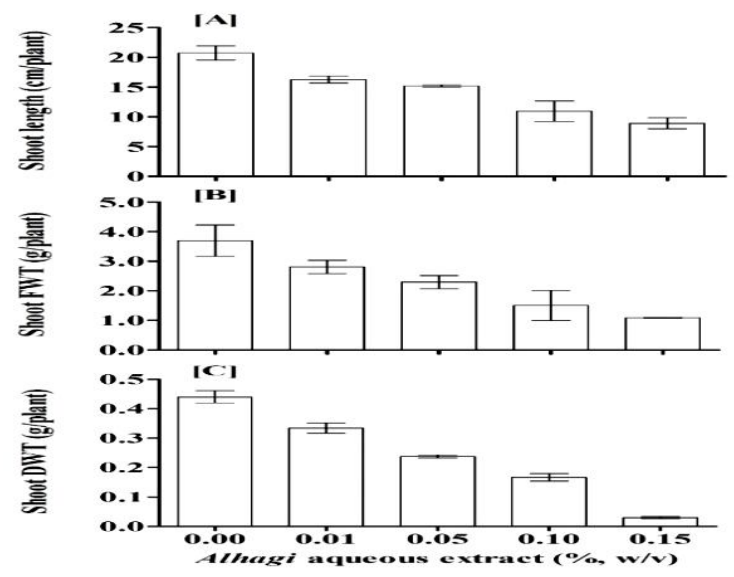

Fig (1) Effect of different concentrations of Alhagi maurorum water extract upon shoot [A] length, [B] fresh weight, [C] dry weight of 45-day-old pea plants. The bars on each column showed standard error. Value $=$ mean \pm SE, $n=5$.
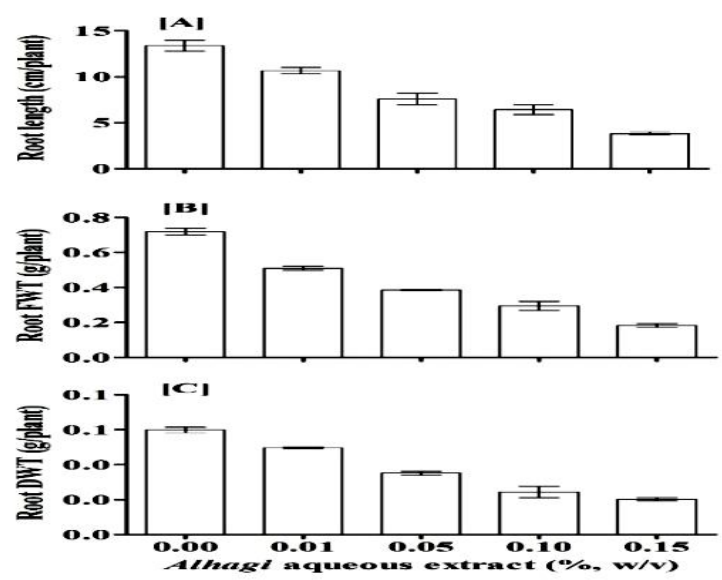

Fig (2) Effect of different concentrations of Alhagi maurorum water extract upon root [A] length, [B] fresh weight, [C] dry weight of 45-day-old peaplants. The bars on each column showed standard error. Value $=$ mean $\pm \mathrm{SE}, \mathrm{n}=5$. 

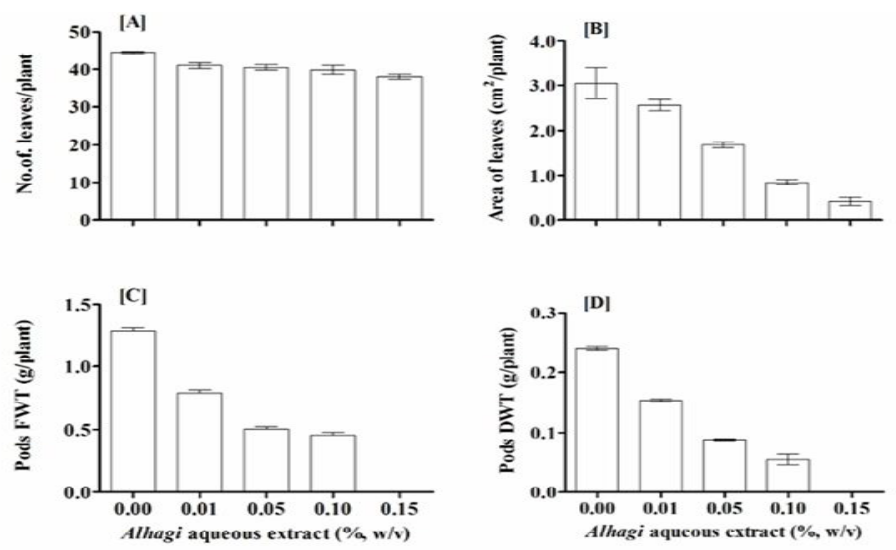

Fig (3) Effect of different concentrations of Alhagi maurorum water extract upon [A] number of leaves, [B] leaf area, [C] pods fresh weight, [D] pods dry weight of 45-day-old pea plants. The bars on each column showed standard error. Value $=$ mean \pm SE, $n=5$.
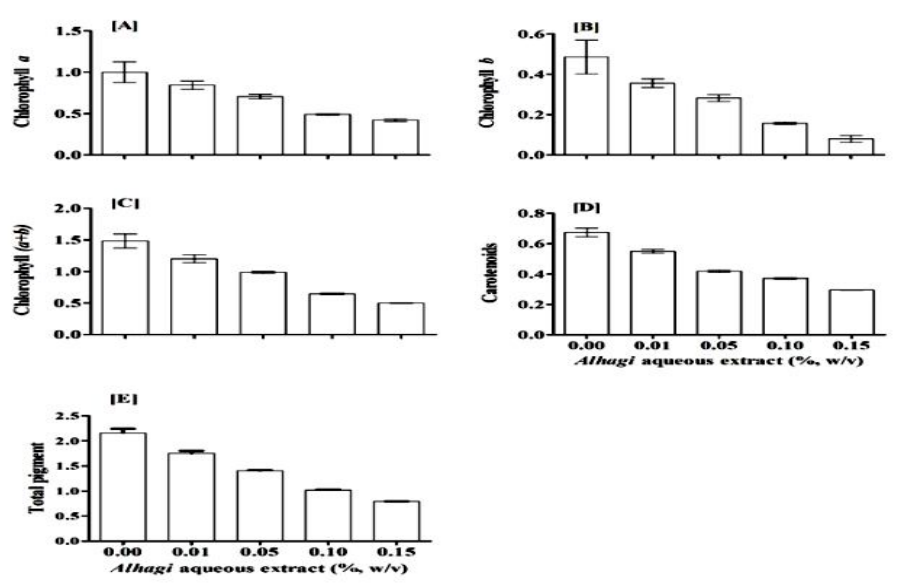

Fig (4) Effect of different concentrations of Alhagi maurorum water extract upon photosynthetic pigments (mg g-1 FWT) [A] chlorophyll a, [B] chlorophyll b, [C] chlorophyll $(\mathrm{a}+\mathrm{b}),[\mathrm{D}]$ carotenoids, [E] total pigment of 45-day-old peaplants. The bars on each column showed standard error. Value $=$ mean $\pm \mathrm{SE}, \mathrm{n}=5$.
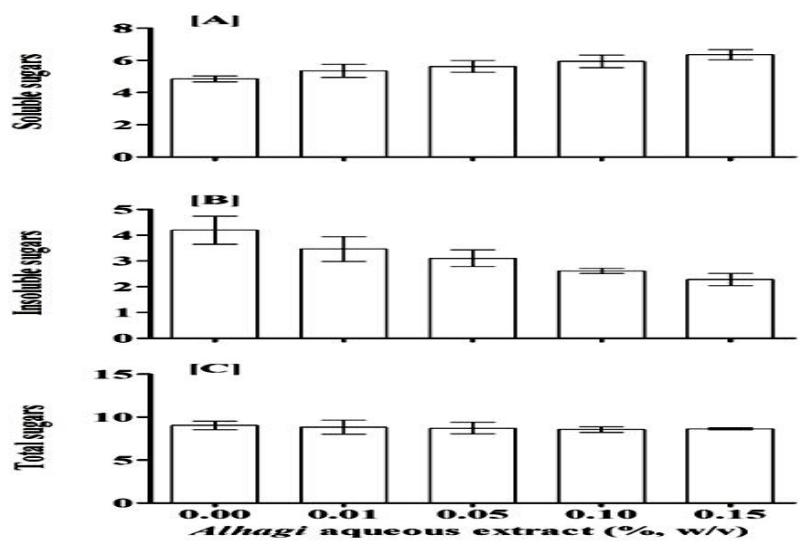

Fig(5) Effect of different concentrations of Alhagi maurorumwater extract upon carbohydrates (mg glucose g-1 DWT) [A] soluble sugars, [B] insoluble sugars of 45-day-old peaplants. The bars on each column showed standard error. Value $=$ mean $\pm S E, n=5$. 


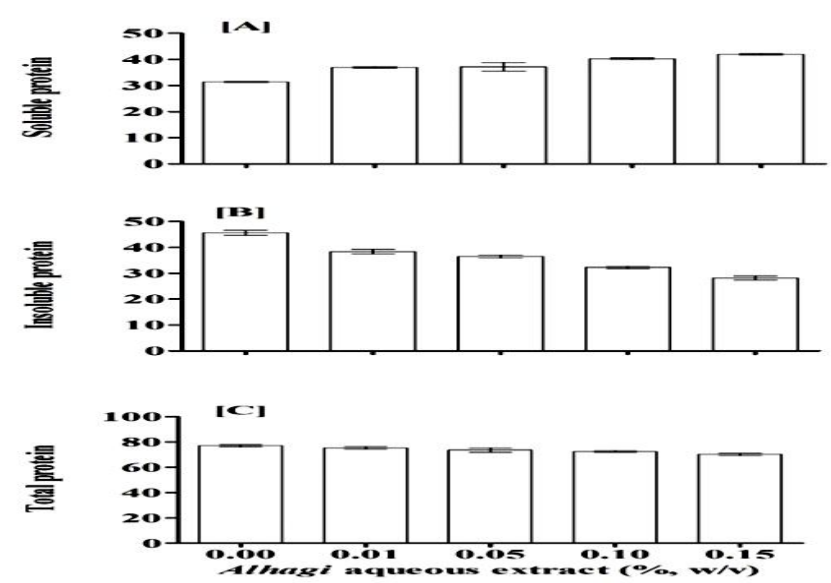

Fig (6) Effect of different concentrations of Alhagi maurorum water extract upon shoot protein (mg g-1 DWT) [A] soluble protein, [B] insoluble protein, [C] total proteinof 45-day-old peaplants. The bars on each column showed standard error. Value= mean $\pm \mathrm{SE}, \mathrm{n}=5$.

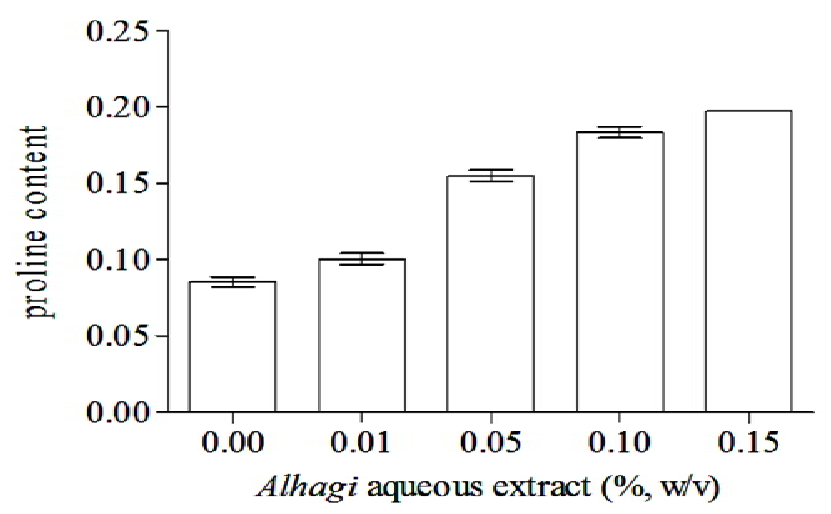

Fig(7) Effect of different concentrations of Alhagi maurorumwater extract upon proline content (mg g-1 FWT) of 45-day-old peaplants. The bars on each column showed standard error. Value $=$ mean $\pm \mathrm{SE}, \mathrm{n}=5$.

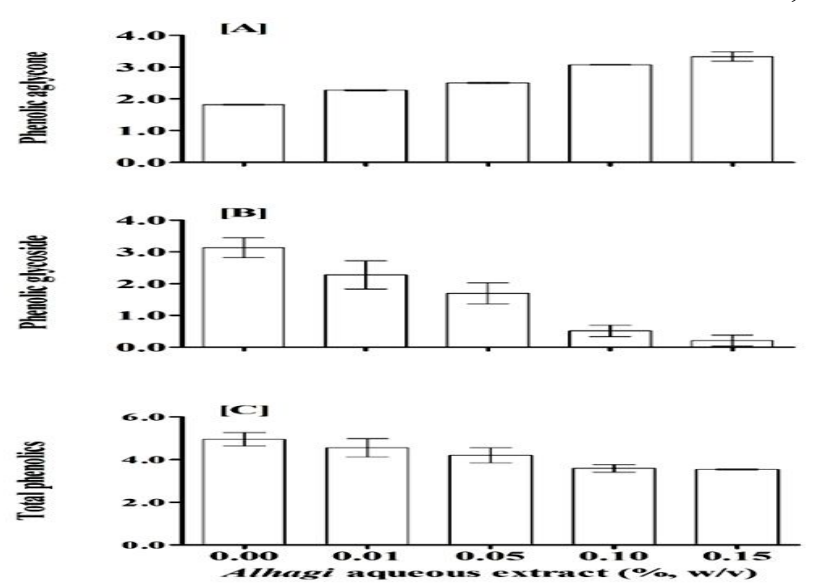

Fig (8) Effect of different concentrations of Alhagi maurorum water extract upon shoot phenolics (mg g-1 DWT) [A] aglycones, [B] glycosides, [C] total phenolicsof 45-dayold peaplants. The bars on each column showed standard error. Value $=$ mean $\pm \mathrm{SE}, \mathrm{n}=5$. 


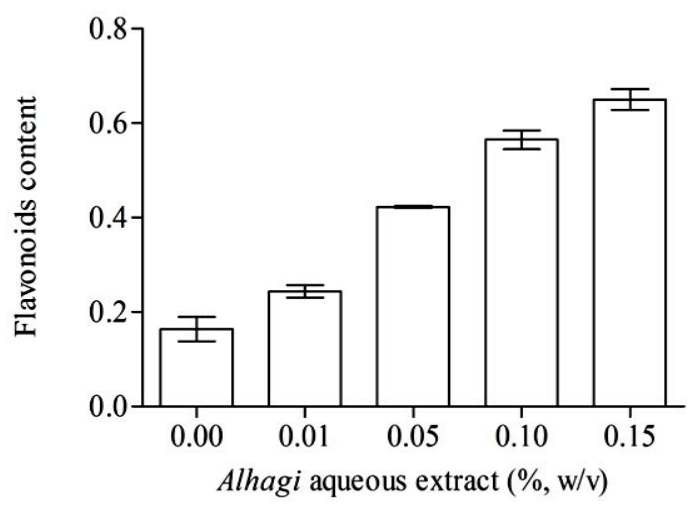

Fig (9) Effect of different concentrations of Alhagi maurorum water extract upon flavonoids content (mg g-1 DWT) of 45-day-old pea plants. The bars on each column showed standard error. Value $=$ mean $\pm \mathrm{SE}, \mathrm{n}=5$.

\section{Conclusion}

From the present results, it can conclude that allelopathic effects of the aqueous extract of the A.maurorum shoots suppresses germination and seedling growth of the target species (Pisum sativum L.). This inhibition was concentration- and species- dependent.

\section{Reference}

[1] E. L. Rice, "Allelopathy. 2nd (ed.) Acad. Press," Inc. Orlando. Florida, USA, 1984.

[2] C.-H. Chou, "Introduction to allelopathy," in Allelopathy, Springer, pp. 1-9, 2006.

[3] A. Tanveer et al., "Allelopathic potential of Euphorbia helioscopia L. against wheat (Triticum aestivum L.), chickpea (Cicer arietinum L.) and lentil (Lens culinaris Medic.)," Turkish J. Agric. For., vol. 34, pp. 75-81, 2010.

[4] R. Harun, J. W. S. Yip, S. Thiruvenkadam, W. A. Ghani, T. Cherrington, and M. K. Danquah, "Algal biomass conversion to bioethanol-a step-by-step assessment," Biotechnol. J., vol. 9, pp. 73-86, 2014.

[5] T. L. Weir, S.-W. Park, and J. M. Vivanco, "Biochemical and physiological mechanisms mediated by allelochemicals," Curr. Opin. Plant Biol., vol. 7, pp. 472-479, 2004.

[6] Z. Iqbal, S. Hiradate, A. Noda, S.-I. Isojima, and Y. Fujii, "Allelopathy of buckwheat: assessment of allelopathic potential of extract of aerial parts of buckwheat and identification of fagomine and other related alkaloids as allelochemicals," Weed Biol. Manag., vol. 2, pp. 110-115, 2002.

[7] J. Li et al., "Potential allelopathic effects of volatile oils from Descurainiasophia (L.) Webb ex Prantl on wheat," Biochem. Syst. Ecol., vol. 39, pp. 56-63, 2011.

[8] A. M. Saleh, "In vitro assessment of allelopathic potential of olive processing waste on maize (Zea mays L.)," Egypt. J. Exp. Biol, vol. 9, pp. 35-39, 2013.
[9] F. E. Dayan, C. L. Cantrell, and S. O. Duke, "Natural products in crop protection," Bioorg. Med. Chem., vol. 17, pp. 4022-4034, 2009.

[10] J. R. Vyvyan, "Allelochemicals as leads for new herbicides and agrochemicals," Tetrahedron, vol. 58,pp. 1631-1646, 2002.

[11] H. M. El-Shora and A. M. Abd El-Gawad, "Response of Cicer arietinum L. to Allelopathic effect of Portaulaca oleracea L. root extract," Phyton (B. Aires)., vol. 55, pp. 215-232, 2015.

[12] E. Saadaoui, J. J. Martin, N. Ghazel, C. Ben Romdhane, N. Massoudi, and E. Cervantes, "Allelopathic Effects of Aqueous Extracts of Ricinus communis L. on the Germination of Six Cultivated Species," Int. J. plant soil Sci., vol. 7, pp. 220-227, 2015.

[13] Z. A. Cheema, A. Khaliq, and S. Saeed, "Weed control in maize (Zea mays L.) through sorghum allelopathy," J. Sustain. Agric., vol. 23, pp. 73-86, 2004.

[14] J. Iqbal, Z. A. Cheema, and M. An, "Intercropping of field crops in cotton for the management of purple nutsedge (Cyperus rotundus L.)," Plant Soil, vol. 300, pp. 163171, 2007.

[15] M. Jamil, Z. A. Cheema, M. N. Mushtaq, M. Farooq, and M. A. Cheema, "Alternative control of wild oat and canary grass in wheat fields by allelopathic plant water extracts," Agron. Sustain. Dev., vol. 29, pp. 475-482, 2009.

[16] M. Farooq, M. Habib, A. Rehman, A. Wahid, and R. Munir, "Employing aqueous allelopathic extracts of sunflower in improving salinity tolerance of rice," J Agric Soc Sci, vol. 7, pp. 75-80, 2011.

[17] P. B. S. Bhadoria, "Allelopathy: a natural way towards weed management," Am. J. Exp. Agric., vol. 1, pp. 7-20, 2011.

[18] M. Farooq, S. M. A. Basra, A. Wahid, N. Ahmad, and B. A. Saleem, "Improving the drought tolerance in rice (Oryza sativa L.) by exogenous application of salicylic acid," $J$. 
Agron. Crop Sci., vol. 195, pp. 237-246, 2009.

[19] D. Zohary, M. Hopf, and others, Domestication of plants in the old world: the origin and spread of cultivated plants in West Asia, Europe, and the Nile Valley, no. Ed. 3. Oxford University Press, 2000.

[20] T. H. N. Ellis, J. M. I. Hofer, G. M. Timmerman-Vaughan, C. J. Coyne, and R. P. Hellens, "Mendel, 150 years on," Trends Plant Sci., vol. 16, pp. 590-596, 2011.

[21] P. H. Graham and C. P. Vance, "Legumes: importance and constraints to greater use," Plant Physiol., vol. 131, pp. 872-877, 2003.

[22] C. S. Awmack and J. M. Lock, "The genus Alhagi (Leguminosae: Papilionoideae) in the Middle East," Kew Bull., vol. 57, pp. 435-445, 2002.

[23] A. M. Hassanein and A. M. A. Mazen, "Adventitious bud formation in Alhagi graecorum," Plant Cell. Tissue Organ Cult., vol. 65, pp. 31-35, 2001.

[24] A. S. Awaad Amani, D. J. Maitland, and G. A. Soliman, "Antiulcerogenic Activity of Alhagi maurorum.," Pharm. Biol., vol. 44, pp. 292296, 2006.

[25] M. K. G. Naseri and S. A. Mard, "Gastroprotective effect of Alhagi maurorum on experimental gastric ulcer in rats.," PAKISTAN J. Med. Sci., vol. 23, pp.570-573, 2007.

[26] I. M. Chung et al., "Screening of allelochemicals on barnyardgrass (Echinochloa crus-galli) and identification of potentially allelopathic compounds from rice (Oryza sativa) variety hull extracts," Crop Prot., vol. 21, pp. 913-920, 2002.

[27] J. Q. Yu, S. F. Ye, M. F. Zhang, and W. H. $\mathrm{Hu}$, "Effects of root exudates and aqueous root extracts of cucumber (Cucumis sativus) and allelochemicals, on photosynthesis and antioxidant enzymes in cucumber," Biochem. Syst. Ecol., vol. 31, pp. 129-139, 2003.

[28] F. Elisante, M. T. Tarimo, and P. A. Ndakidemi, "Allelopathic Effect of seed and leaf aqueous extracts of Datura stramonium on leaf chlorophyll content, shoot and root elongation of Cenchrus ciliaris and Neonotonia wightii," Am. J. Plant Sci., vol. 4, pp. 2332-2339, 2013.

[29] A. Mishra, "Allelopathic properties of Lantana camara," Int. Res. J. Basic Clin. Stud., vol. 3, , pp. 13-28, 2015.

[30] S. Growth, M. Mp, V. Pal, S. Kumar, and M. Sk, "Research and Reviews $\square$ : Journal of Botanical Sciences Allelopathic Effects of Leaf Extracts of Kalmegh on Seed," vol. 5, pp. 2014-2017, 2016.

[31] N. A. Barakat and H. Nazeir, "Growth And
Physiological Response Of Some Cultivated Species Under Allelopathic Stress Of Calotropis procera (Aiton) W.T.," Appl. Sci. Reports, vol. 14, 2016.

[32] D. Singh and Y. B. N. Rao, "Allelopathic evaluation of Andrographis paniculata aqueous leachates on rice (Oryza sativa L.)," Allelopath. J., vol. 11, pp. 71-76, 2003.

[33] N. B. Singh and S. Rao, "Residual effects of Mentha piperita L. on growth and metabolism of rice seedlings," Sci. Agric., vol. 10, pp. 151-155, 2015.

[34] M. S. S. and H. M. Md. Kashedul, S. Shahriar, A.S.M. Fazle Bari, "Plant Nutrient Status of Nerica 10 Under Integrated Fertilizer Management Md.," Sci. Agric., vol. 11, pp. 145-150, 2015.

[35] R. M. Wallsgrove, Amino acids and their derivatives in higher plants, vol. 56. Cambridge University Press, 1995.

[36] M. M. Y. Madany and A. M. Saleh, "Phytotoxicity of Euphorbia helioscopia L. on Triticum aestivum L. and Pisum sativum L.," Ann. Agric. Sci., vol. 60, pp. 141-151, 2015.

[37] T. Vaithiyanathan, M. Soundari, M. Rajesh, K. S. Ganesh, and P. Sundaramoorthy, "Allelopathic effect of Azadirachta indica L.on germination of Abelmoschus esculentus L.," Int. Lett. Nat. Sci., vol. 15, pp. 13-22, 2014.

[38] A. Scalbert and G. Williamson, "Dietary intake and bioavailability of polyphenols," J. Nutr., vol. 130 ,p. 2073S--2085S, 2000.

[39] C. Sánchez-Moreno, "Compuestos polifenólicos: Estructura y clasificación. Presencia en alimentos y consumo. Biodisponibilidad y metabolismo," Alimentaria, vol. 329, pp. 19-27, 2002.

[40] P. C. H. Hollman, "Evidence for health benefits of plant phenols: local or systemic effects?," J. Sci. Food Agric., vol. 81, pp. 842$852,2001$.

[41] C. A. Williams and R. J. Grayer, "Anthocyanins and other flavonoids," Nat. Prod. Rep., vol. 21, pp. 539-573, 2004.

[42] J.-L. Ferrer, M. B. Austin, C. Stewart, and J. P. Noel, "Structure and function of enzymes involved in the biosynthesis of phenylpropanoids," Plant Physiol. Biochem., vol. 46, pp. 356-370, 2008.

[43] S. Pollastri and M. Tattini, "Flavonols: old compounds for old roles," Ann. Bot., vol. 108, pp. 1225-1233, 2011.

[44] P.-M. Delaux, A. K. Nanda, C. Mathé, N. Sejalon-Delmas, and C. Dunand, "Molecular and biochemical aspects of plant terrestrialization," Perspect. Plant Ecol. Evol. Syst., vol. 14, pp. 49-59, 2012. 